\title{
LA TEORÍA LITERARIA DEL COMPROMISO EN LA REVISTA «AL-ĀDĀB»
}

\author{
Por \\ JUAN ANTONIO PACHECO PANIAGUA
}

En una teoría destinada a reflexionar sobre el hecho de la creación literaria y sus motivaciones últimas, el yo que escribe, el yo que lee, el yo que juzga y el yo que se lee, establecen una correlación dialéctica cuyo lugar de encuentro final es el producto definitivamente terminado y perfecto que conocemos como «obra literaria». La literatura árabe contemporánea y teniendo en cuenta sus especiales condicionantes sociológicos e ideológicos, nos ofrece un sugestivo campo de estudio en el que es posible observar con nitidez los diversos planos sobre el que esos diferentes sujetos se encuentran. De ese encuentro resultará una literatura comprometida, como dice Halim Barakāt, en la exploración crítica de la sociedad árabe, llevada a cabo por «críticos creativos sobre su propia sociedad y no por partidarios del orden establecido» (1).

Así, nos es posible observar en numerosos textos literarios árabes contemporáneos ese juego dialéctico, previo al acto de escritura, pero que sin el cual los planos del yo apuntados no pueden manifestarse. En la poesía, por ejemplo, disponemos de un amplio muestrario de esa red de consciencias literarias: el poema de Badr Šākir al-Sayyäb, Jaykür wa-l-madinna, donde un mismo yo que narra encarna sujetos plurales en lucha con el orden del mundo (2), o el poema de Fadwā Tưuāan, Amāma al-bāb al-muglaq, donde la característica fundante del yo narrativo aparece como pretensión de constituirse como cosmo significativo en relación a algo que lo trasciende.

Todos los estudiosos o lectores de literatura árabe contemporánea saben que no solamente en poesía, sino también en prosa o drama, existen numerosos ejem-

(1) BARAKAT, H.: Visions of Social Reality in the Contemporary Arab Novel, Georgetown, 1977, p. 4.

(2) BADR ŠĀKIR AL-SAYYÄB: Diwän, Beirut, 1971. 
plos y paradigmas que, en cualquier caso, determinan que la creación literaria árabe de nuestro siglo es, por debajo de su evidente connotación social, un hecho individualmente enigmático y dependiente, muchas veces, de factores que no aparecen en el seno mismo del hecho social o del componente ideológico. En cierto modo, el dilema que plantea la creación literaria en el contexto de la sociedad y de la historia ya fue apuntado, en la literatura árabe del siglo $\mathrm{X}$, por Ibn al-Mu'tazz en su obra Kitāb al-Badī' donde compara el origen creativo de la poesía 'abbasī con el fundamento originario de la poesía antigua (3).

En el caso de la literatura árabe contemporánea, o al menos, de un sector muy extenso y decisivo de la misma, el problema de la creación literaria adquiere características genuinas en tanto que esa literatura viene señalada con el marchamo de «literatura comprometida». El ingrediente político o ideológico de la misma y, en muchos casos, generador del impulso creativo, quedó claramente expuesto en la conferencia que, sobre la novela árabe, tuvo lugar en Fez en el año 1979 (4). En el transcurso de la mencionada conferencia, 'Abd al-Rahmān Munif, Suhayl Idriss, 'Abd alKarīm Galläb, Eduar al-Jarrāt y Sun 'Allāh Ibrāhīm, entre otros, relataron su propia experiencia creativa en el contexto del momento social que les tocó vivir. Veinte años antes, Tawiīq al-Hakim, en una reflexión sobre la creatividad de su generación literaria, nos ofrecía algunos de los parámetros significativos de la literatura del compromiso, refiriéndose a la vez al núcleo mismo de la motivación literaria:

«Éramos - decía el autor de Al-jurüŷ min al-yanna- una generación de mártires (...), gente que se autoinmolaba y que derrochaba sus vidas en una búsqueda imposible (...). Por eso nos vimos forzados a escribir sin tregua, ensuciando blancas hojas de papel con inútiles borrones (5).

El interés de la cita de Tawfīq al-Hakim radica, ante todo, en que el acento de su reflexión está puesto en el impulso originario que motiva la escritura y en el sentido y alcance que subyace a la misma. Al considerar las relaciones intencionales que se establecen en toda obra posible para su generación, entre el sujeto constituyente y la obra constituida, el vacio que parece existir entre la obligatoriedad de escribir y la búsqueda imposible con lo escrito, se colma con el sentido. Tras él, toda una teoria incipiente, pero decisiva, sobre lo que debe entenderse por literatura comprometida, llenará las páginas de crítica literaria de la revista $A /-\bar{A} d \bar{a} b$ en la década de los años cincuenta (6).

Del análisis realizado, en una primera aproximación, sobre el corpus teórico de la literatura comprometida que se expone en la revista $A /-\bar{A} d \bar{a} b$ surge enseguida un paralelismo evidente con algunas teorías literarias vigentes en Europa por la misma época y, sobre todo, una similitud muy clara de planteamientos con la teoria de la literatura expuesta por Jean Paul Sartre en Francia.

(3) IBN AL-MU'TAZZ: Kitab al-Badic, Ed. I. KRATCHKOVSKY, Londres, 1935.

(4) Un informe detallado de las propuestas y conclusiones de la conferencia aparece en $A / \bar{A} d \bar{a} b$ (febrero y marzo de 1980) y en el número siguiente de abril-mayo.

(5) De una entrevista publicada en $A /-\bar{A} d a ̈ b$ (1957), marzo, p. 14. El subrayado es mio en todos los casos.

(6) El tema, planteado para el teatro árabe, aparece en el artículo de $A l-\bar{A} d \bar{a} b$ : «Asbäb ḍaff al-masrahilyya al(arabiyya al-haditas (1953), julio, pp. 20-25. 
Las expresiones «literatura comprometida»y «compromiso literario» definen uno de los rasgos que caracterizan el pensamiento árabe contemporáneo. Como sabemos, ese pensamiento encontrará, a su vez, el medio expresivo idóneo en la literatura que, por ello mismo, será literatura del compromiso social o ideológico. La revista Al-ĀAàb que será portavoz, desde sus primeros años de publicación, de ese compromiso literario, manifiesta explícitamente: «En esta revista preconizamos la consolidación de una literatura iluminada y dirigida por el compromiso» (7), si bien, como hemos dicho anteriormente, este compromiso que Suhayl Idriss plantea como condición programática de la creación literaria, remite muy directamente al compromiso literario y a la teoría de la literatura de Sartre.

Las reflexiones teóricas sobre la literatura del autor de La Náusea aparecen en el año 1948, en el volumen Situations // de la edición de Gallimard (8). En ese momento, Sartre estudia la cuestión de la naturaleza y finalidad de la literatura en base a tres momentos fundamentales del acto de escritura: ¿qué es escribir?, ¿por qué escribir? y ¿para quién escribir? En 1954, la revista $A / \bar{A} d a ̄ b$ publica un artículo que intenta dar respuesta a estas tres cuestiones desde la perspectiva de la crucial experiencia social y literaria árabe del momento. El autor del artículo, Ra'îf al-Jūrĭ, interpela al escritor árabe indagando por la naturaleza de su motivación literaria (9). La exposición de al-Jūri contiene marcados rasgos programáticos y puede considerarse como un intento de fundamentar y estructurar, coherentemente, la naturaleza misma de la literatura comprometida. Para Ra'if al-Jürī, en el horizonte de lo que pudiéramos denominar condiciones de posibilidad de la experiencia literaria, la vida representa el elemento originario de la obra escrita, si bien este concepto fundante es para el autor el conjunto de factores que brotan de la sociedad siendo, «la búsqueda del sentido de esta vida la que marcará el primer objetivo del hecho literario» (10).

La creación literaria, dice Ra'if al-Jūri, no se origina fuera de la historia ni fuera de la experiencia de lo real, ni tampoco anula los valores semánticos, las dimensiones sociales y simbólicas que forman parte integrante de los signos de la lengua de la que el texto literario es solamente una realización particular y especifica (11). Si bien toda literatura comporta una inevitable actitud previa ante el mundo, ello no implica una imposición externa indiscriminada y alienante. En realidad, la literatura es el campo donde la experiencia personal es absolutamente insustituible, un conocimiento que no puede suplantarse por coacción externa alguna, aunque ésta fuera la mejor pensada del mundo y la más convicente.

Planteada en estos términos, la teoría literaria de al-Jūrì se mueve en un doble plano constituido por los aspectos de objetividad y subjetividad que el sociologismo vulgar o algunas modalidades de historicismo tienden a confundir reduciéndolo todo

(7) SUHAYL IDRTS: «Risālat $A / \bar{A} d \bar{a} b », A /-\bar{A} d \bar{a} b$ (1953), enero, pp. 1-2.

(8) La primera edición castellana de esas reflexiones con el título: ¿Qué es la Literatura?, es la de Ed. Losada, Buenos Aires, octubre de 1950. En este trabajo me remito siempre a dicha traducción castellana en su edi-
ción de 1967 .

(9) RA'IF AL-JŪRI: «Ayyuhā al-adỉb, man anta?», Al-Ādäb (1954), noviembre, pp. 1-4.

(10) lbid, p. 2.

(11) Ibid, p. 2. 
a una pura historicidad (12). Según al-Jūri, el escritor parte de una dicotomía vital: lo social y lo personal o individual y su armonización en una sintesís unitaria constituye la mejor defensa de la libertad personal contra la coerción externa. Dicha conciliación deberá expresarse en lo que el autor del artículo denomina la «apertura» a la sociedad, a la nación, al pueblo y al momento histórico: «El escritor debe vivir con las ventanas de su espíritu abiertas a las circunstancias que lo rodean» (13).

En un intento por acercarse más a la raíz del impulso literario, en el mismo número de noviembre de 1954 de $A /-\bar{A} d \bar{a} b$, aparece una encuesta titulada: Li-man wa-limāda taktub? (14), a la que responderán escritores árabes de variada procedencia geográfica y diverso talante intelectual y literario. La intención de $A /-\bar{A} d a ̈ b$ al demandar al escritor el por qué de su escritura, es mostrar cómo el impulso creador del literato árabe se dirige, ante todo, a sus lectores como seres libres, teniendo en cuenta que toda libertad se concretiza en una situación histórica determinada. Esa sería, por otra parte, la forma en que el existencialismo literario entiende la libertad creadora. Suhayl Idris manifestaba, poco antes de la aparición de la mencionada encuesta en las páginas de su revista, que si escribir y leer son correlatos encuadrados en un mismo fenómeno, es necesrio que la situación asumida por el autor al inicio de su obra no sea ajena a la situación del lector (15).

Teniendo en cuenta el amplio espectro de figuras literarias a las que va dirigida la pregunta de $A l-\bar{A} d \bar{a} b$, las respuestas a la misma oscilan entre la total ausencia de fundamento teórico para el origen de la obra literaria y la completa y elaborada teoría previa al acto de escribir. Así, 'Alí Ahdam dirá, por ejemplo, que no hay más origen de la creación literaria que un impulso irracional o ciego que no parece ni pretende ser dirigido a nadie en especial: «No sé exactamente para quién ni por qué escribo» (16). «Me pregunto para quién y para qué escribo y ni yo mismo lo sé», responderá Sa'Td Taqi al-Dín (17). Más cercana a la motivación social será la postura de Yusuf Gușüb: «A nadie se le oculta que la situación social, las costumbres y los hábitos de la gente, con sus avenencias y desavenencias reciprocas, constituyen el elemento fundamental de las novelas, y del teatro» (18). Otras respuestas aluden a la subjetividad del creador como es el caso de Šākir Muștafà: "Creo que la literatura es una necesidad humana básica (...). Escribo para iluminar a lo que de oscuro hay en mí» (19), o el de Muḥyī-I-Dīn Ismāîl: «El escritor auténtico es el que adopta una actitud ética y humanista, escribiendo para el hombre en cuanto que es hombre» (20).

Sin embargo, será el teórico de la estética Šākir Hasan Sa'Td quien desarrolle

(12) Vid. también, SUHAYL IDRTS: «Nahnnu wa-lfann», Al-Ädäb (1956), enero, p. 3

(13) RA'TF AL-JÜRT, op. cit., p. 2. Véanse también estas ideas del autor comparándoias con las expuestas por G. LUKÀCS en La Signification du réalisme critique, Gallimar, Paris, 1960, pp. 199.

(14) Al-Ādāb (1954), noviembre, pp. 1-5.

(15) SUHAYL IDRIS: «Ra'y fĩ-l-gișas al-fā'iza», Al-Adab (1954), marzo p. 33. La misma tendencia teórica permanece casi intacta veinte años después, como puede verse en (ABD-ALLÄH SARITT, «Al-adīb al-(rabī bayn al hurriyya wa-l-muytama ${ }^{\prime}$, Al-Ädáb (1975), mayo, pp. 34-35.

(16) Li-man wa-lima taktub, op. cit., p.2

(17) lbid., p. 2.

(18) Ibíd., p. 2.

(19) Ibid., p. 3.

(20) Ibid., p. 3. 
una teoría literaria más elaborada, en la línea de las ideas expuestas por Ra îf alJūri y muy cercana a la propuesta de Jean Paul Sartre (21). Para el autor, en la cúspide de la motivación originaria de la escritura aparece la libertad como exigencia incondicionada respecto de sí misma, del autor y de los lectores posibles:

«Me dirijo al hombre libre, pues lo que él lee no adquiere entidad si soy yo sólo el que lo da por hecho. Lo que emite el fallo definitivo es lo que leen los demás. Sea lo que fuere lo que escritor defina o delimite, siempre será una semilla que germinará en la formación del lector y de la que brotarán sus visiones del mundo y sus opiniones. Se trata, en definitiva, de una nueva vida que recibe un hombre libre a partir de las impresiones que le proporciona otro hombre libre» (22).

Y no otra cosa dice Sartre al referirse a los supuestos inmediatos de que todo autor debe partir:

«El autor escribe para dirigirse a la libertad de los lectores requiriéndola a fin de que haga existir la obra. Pero no se limita a esto y reclama además que se le devuelva la misma confianza, que se le reconozca su libertad creadora y que se la pidan a su vez por medio de un llamamiento simétrico e inverso. Aquí se manifiesta, en efecto, la otra paradoja dialéctica de la lectura: cuanto más experimentamos nuestra libertad, más reconocemos la del otro; cuanto más nos exige, más le exigimos» (23).

Hasan Sa'id y Sartre coinciden, en este aspecto, casi literalmente: quien escribe reconoce, por el mismo hecho de que se tome el trabajo de escribir, la libertad de sus lectores y quien lee reconoce la libertad del escritor. En este sentido, la obra literaria puede definirse como «una presencia imaginaria del mundo en la medida en que éste exige la libertad humana» (24). Tampoco hay que olvidar que Hasan Sa'id teoriza sobre la literatura teniendo muy presente que el objeto literario, aunque se realice a través del lenguaje, no se halla jamás en el mismo:

«Todo ésto no impide que la literatura sea la expresión de algo susceptible de ser leido con un fin determinado, con lo que su contenido puede dilatarse indefinidamente (...). La escritura es, en este sentido, lo más parecido al perfume de las flores (...). El escritor escribe para el otro sin restricciones ni cortapisas. La diferencia final radicará entre el tonto y el listo, entre el iletrado y el culto, de la misma forma que existe entre el ser libre que se comprende a sí mismo y el que está lleno de limitaciones" (25).

Sobre el «sentido» de lo escrito, dice Sartre también: «No se debe creer, en efecto, que la lectura sea una operación mecánica y que esté impregnada por los signos como una placa fotográfica suele estarlo por la luz. Si el lector está distraído o cansado, si es tonto o atolondrado, la mayor parte de las relaciones se le escaparán (...). Si el lector está en las mejores condiciones posibles, proyectará más allá de las palabras una forma sintética de la que cada frase no será más que una función parcial» (26).

(21) También pueden verse las mismas ideas en su artćulo: «Dirāsa fïl-fann al-)irqäqī al-mu(äșir», Al-Ādäb (1956), diciembre, p. 31.

(22) Li-man wa-limäda taktub, op. cit., p. 2.

(23) J.P. SARTRE, op. cit, p. 74.

(24) Ibid., p. 82.

(25) Li-man..., op. cit., p 2.

(26) SARTRE, op. cit., p. 69 
Afirma Sartre que el escritor parte de un universal abstracto compuesto por la totalidad de los lectores posibles y que, posteriormente, el acto concreto de lectura singulariza los elementos del universo/universal intencional: «De la diferencia entre el público ideal y el público real ha nacido la idea de la universalidad abstracta» (27). De ahí surge, en el trabajo del escritor, una aparente contradicción entre lector ideal y lector real a la que alude Šăkir Hasan Sa'īd:

«Escribimos para el lector que lee nuestros libros y que los vive como nosotros los vivimos. Este sería el lector ideal, el lector que deseamos. Pero escribimos también para otro tipo de lector que vive nuestros libros como él mismo lo desea y no como queremos nosotros. Pero, ¿es qué no queremos que exista también este tipo de lector? De aquí se deriva la responsabilidad real del escritor que debe ponderar el efecto de sus obras en los demás y cargar con las consecuencias. Entonces, deberá tener bien claro que, como escritor, escribe para toda la humanidad» (28).

En la universalidad del acto de escritura, el escritor opta por apelar a la libertad de los demás para que no eludan, ni él tampoco, el compromiso que esa escritura conlleva: «Asumimos la responsabilidad de la escritura que produce unos efectos. Creemos en la eficacia de la escritura, en su influencia» (29). De la misma forma que Sartre dice que «la palabra es acción. El escritor comprometido sabe que revelar es cambiar y que no es posible revelar sin proponerse el cambio» (30).

Lejos de cualquier tentación irracionalista, Sartre subraya que no es verdad que se escriba para sí mismo. «Sería el mayor de los fracasos: al proyectar las emociones sobre el papel, apenas se lograría procurarles una lánguida prolongación. El acto creador no es más que un momento incompleto (...), pues la operación de escribir supone la de leer como su correlativo dialéctico y estos dos actos conexos necesitan dos agentes distintos" (31). Šakir Hasan Sa'id opta también por el esfuerzo conjugado de autor y lector:

«Escribimos para actualizar nuestro ser del modo más amplio posible, así como el lector, a su vez, debe actualizar su existencia. La lectura, como acto, es el correlato de la escritura, pues ambos constituyen los medios para una integración unitaria. La escritura, por tanto, no es un compromiso parcial que el escritor sugiere al lector, sino que por medio de la escritura, el escritor también se comprometen (32).

Una vez planteada la escritura como acto intencional, el grado más alto de compromiso a que se puede llegar es el del lector «comprometido consigo mismo a través de nuestra obra» (33), o, como dice Sartre, «la exigencia del autor consiste en que yo lleve mis exigencias al más alto grado. Así, mi libertad, al manifestarse, revela la libertad del otro" (34). Para Šakir Hasan Sa'îd es fundamental que comprendamos que la primera función de la escritura es el mutuo entendimiento entre escritor

\footnotetext{
(27) lbid., p. 145.

(28) Li-man..., op. cit., p. 2.

(29) Ibid., p. 2.

(30) SARTRE, op. cit., p. 53

(31) Ibid, p. 68.

(32) Li-man..., op. cit. p. 2.

(33) lbid., p. 3.

(34) SARTRE, op. cit., p. 77
} 
y lector, «escribo para que mi obra sea leída, pero esta lectura es, a su vez, un mundo nuevo que el lector libre re-vive» (35), de la misma forma que para Sartre escribir es pedir al lector «que haga pasar a la existencia objetiva la revelación que yo he emprendido por medio del lenguaje. Así el escritor recurre a la libertad del lector para que ella colabore en la producción de la obras (36).

A la pregunta de para quién y para qué escribir que propone la revista $A$ /$\bar{A} d a ̈ b$, pocos son, sin embargo, los escritores que inciden en los valores transformadores que el escritor árabe debe aportar a su época, en el sentido en que la filosofía existencial de cuño sartriano manifiesta los únicos objetos susceptibles de ser tratados literariamente: el mundo, los demás, la historia, la verdad, la cultura. Así entendida, la experiencia literaria se produce siempre en una comunidad o colectividad actual o virtual necesitada, en último término, de transformación dinámica. En un artículo de enero de 1960, Suhayl Idris manifiesta la necesidad de que el escritor árabe se dirija a su hermano de raza, también de clase y, sobre todo, de patria, invitándole a colaborar en la transformación del mundo (37). Según Idris, ha llegado el momento de sustituir la literatura de hexis, de consumo, placer o entretenimiento, por la literatura de praxis, literatura de acción en la historia y sobre la historia, para transformar las estructuras de la sociedad árabe. A continuación, el autor se pregunta si hasta el momento el escritor árabe ha cumplido con esa función de creador de conceptos dinámicos en sus lectores a partir de su propia experiencia del mundo y de la vida. La respuesta es negativa y «el más claro ejemplo de ello lo tenemos en la última revolución árabe de Egipto, donde no recordamos ninguna obra literaria importante que haya colaborado en la transformación política que se estaba produciendo" (38).

Para Idris en esta circunstancia, como para Sartre en su momento, hablar es obrar. La realidad nombrada sufre una modificación tan pronto como la palabra la desnuda. La revelación causada por el escritor, implica la transformación de lo revelado comprometiendo en esta empresa la responsabilidad de los otros. En cualquier caso, como indica Ra'îf al-JūrT, se trata de un compromiso libremente asumido:

«No creemos en la obligación, al-ilzām, sino en el compromiso, al-iltizām, que brota de la espontaneidad del escritor y éste, naturalmente, se comprometerá si realmente vive las circunstancias de su época y de su sociedad» (39).

Las ideas que sobre el compromiso del escritor como motivación literaria expuso Muhyyi-l-Dĩn Șubhī en julio de 1962 (40), suscitaron una severa réplica de Tsà alNāữr en el número de la revista del mes siguiente (41). Dice al-Nā̌ürī que MuhyīI-Din Șubḥi habla del escritor y de su obra en términos no específicamente literarios:

«Empieza hablando de la literatura, que, como sabemos, es una de las bellas artes,

(35) Li-man..., op. cit., p. 3.

(36) SARTRE, op. cit., p. 71.

(37) SUHAYL IDRTS: «Asabu-nā al-tawrì, Al-ĀAab (1960), enero, p. 1.

(38) Ibid., p. 1.

(39) RA'IF al-JURT, op. cit., p. 2.

(40) MUHYTil-L-DIN SUBHTT: «Mu'tamar al-adab al-‘arabī al-mu(āsir fi-Roma», Al-Ādäb (1962), julio, pp. 56-57.

(41) En la Sección Lecturas del número anterior, del número de agosto, p. 71. 
y continúa refiriéndose a la política, al socialismo, a la unidad árabe y al marxismo, sin citar para nada el hecho de la literatura como arte, pero que él entiende como medio para realizar una política determinada" (42).

Tsà al-Năüri está de acuerdo en que una de las misiones del escritor es influir, escribir con motivaciones políticas, pero evitando siempre ser guiado por la política y servir a sus ambiciones: «La literatura que se pone al servicio de los objetivos políticos es una literatura que nace muerta y no merece ser leída» (43).

Sin embargo, ya en uno de los primeros números de la revista $A /-\bar{A} d \bar{a} b(44)$, Suhayl Idris, al invocar el compromiso literario, hacía mención de la críticas posibles a su propuesta, del mismo modo que se habian dirigido a la teoría de la literatura comprometida de Sartre: Comprometerse significa coacción sobre la libertad individual y comprometerse literariamente significa sacrificar los aspectos de orden estético en aras del mensaje y de la idea. Idrīs rebate estas acusaciones diciendo que desde el momento en que un escritor vive realmente la vida de su época y vibra con los sentimientos y esperanzas de su sociedad y de su pueblo, proyecta para él, como detentador de un mensaje, un horizonte de ideas que se constituyen como el modelo al que es posible aspirar. A partir de este momento fundante, el escritor siente que su compromiso con la sociedad a la que se dirige es imprescindible para que su acción literaria tenga algún sentido. Pero ese compromiso remite siempre a un acto libre pues, de no serlo, habría que pensar que le viene impuesto desde fuera, lo que representaría una contradicción en los términos. En cuanto a la suposición de que ese compromiso desvirtúa la estética literaria, Idris es tajante al afirmar que la estética como único designio de la literatura es algo vacio y sin sentido:

«La primera condición de la literatura como acto es que sea verídica y sincera. Si es asi, la obra literaria será bella y el orden estético brotará de ella aunque en apariencia no sea hermosas (45).

Si comparamos los planteamientos que sustentan la teoría literaria del compromiso, en los años cincuenta y sesenta, aparecidas en la revista $A l-\bar{A} d \bar{a} b$, con las conclusiones de la conferencia sobre literatura árabe de $\mathrm{Fez}$ a la que aludíamos al principio de este trabajo, veremos cómo las ideas iniciales sobre el escritor y su misión aparecen notablemente decantadas. Las vicisitudes de la experiencia literaria de los autores árabes y la crisis general de su mundo, han dejado una huella profunda y distorsionadora en un programa que fue esperanzado. La cuestión que en Fez se debatía era saber si el escritor árabe de hoy puede hacer frente a esa crisis con garantías de éxito y conocer hasta qué punto esa tarea está sometida a presiones, compromisos y coerciones:

«QQué se espera del escritor y de su palabra al hablar de sus semejantes en la mortal atmósfera de decadencia en que se halla la nación árabe?, ¿debería condenar las estructuras de poder y sus fundamentos, imputándoles la responsabilidad de este declive? En último término, ¿podría expresarse libremente» (46).
(42) Ibid., p. 71
(43) Ibid., p. 71
(44) SUHAYL IDRIS: «Šakawā al-adab al-(arabi al-ḥadit», Al-Ādäb, mayo (1953), pp. 18-20.
(45) Ibid., p. 18.
(46) Véase, SUHAYL IDRïS: «Azmat al-ibdä‘ aydān», Al-Ădäb (1972), diciembre, p. 3. 
El pesimismo de estas reflexiones es evidente al comparar su intención con la teoría de la palabra como condicionante de la acción que hemos comentado. Aún rechazando una historización radical de la actividad literaria, tal como Sartre la expone en 1965 (47), Suhayl Idris nunca dejó de promover una literatura cuya misión suprema era hablar al hombre de su libertad, de su destino y del sentido de la vida y del mundo desde una perspectiva esperanzada y ciertamente humanista. Incluso René Habaši, pensador existencialista libanés, intentó en su momento trascender la ecuación sartriana de palabra igual a acción revolucionaria, proponiendo una creación literaria abierta a la convivencia comunitaria pacífica a pesar de las naturales controversias sociales (48).

La decepción teórica de finales de los años setenta podría demostrar, empíricamente, el hecho de que el escritor árabe ha dependido en numerosas ocasiones de unos condicionamientos que, directa o indirectamente, han tratado de reconducir su tarea. Como indica 'Abd al-Nabī Hiŷazizi, la función permanente del escritor árabe contemporáneo ha sido tanto una confrontación consigo mismo, como una lucha con la sociedad y contra el poder. Los hechos, opina, manifiestan que «la obra escrita se halla siempre expuesta a la censura, a sus caprichos y a las operaciones de edición y ventas. Estos son los factores que a menudo fuerzan al escritor a desistir de su tarea, si bien con la consiguiente amargura y el fatal resentimiento» (49).

(47) Véase el testimonio de SARTRE en el volumen colectivo, Que peut la litérature, Ed. L'Inédit, Paris, 1965, p. 122.

(48) RENĖ HABAŠI: «Al-adab al-(arabi al-hadit bayn al-azma wa-ltaqaddum», Al-Ādab (1954), octubre, p. 1.

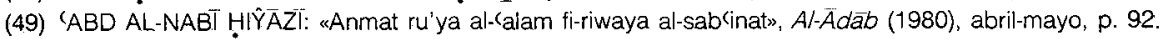

